\title{
OPTIMIZATION OF MICROWAVE ASSISTED DELIGNIFICATION OF WOOD RESIDUES BY SURFACE RESPONSE METHODOLOGY
}

\author{
A. Trifan ${ }^{1}$, I. Calinescu ${ }^{1}$, M. Vinatoru ${ }^{1}$, A. I. Gavrila ${ }^{1}$, \\ ${ }^{1}$ University Politehnica of Bucharest, Faculty of Applied Chemistry and Material Sciences, \\ Bioresources Departament, 1-7 Polizu Gh. Street, Bucharest, Romania \\ adrian.trifan@upb.ro
}

Keywords: microwave, lignin, wood residue

\section{Introduction}

Due to effects such as global warming, environmental pollution and health hazards directly linked with the intensive exploitation of fossil fuels, there is an urgent need to find alternative energy resources. Vegetal biomass is a renewable resource with high availability worldwide. Current research is focused on developing efficient processes to transform this resource into bio-fuels and value-added fine chemicals [1, 2]. Vegetal biomass contains cellulose, hemicellulose and lignin in variable amounts. Pre-treatment plays a major role in breaking down the lignin barrier for the recovery of cellulose from lignocellulosic biomass. The effectiveness of a pre-treatment should be assessed following some criteria: minimizing energy input and the formation of inhibitors; maximizing the yield of fermentable sugars and preservation of cellulosic and hemicellulosic fractions [3]. There are several options of pre-treatment for lignocellulosic biomass and among them the most promising are: mineral acids, alkali, organosolv, wet oxidation, $\mathrm{CO}_{2}$ and steam explosion. A considerable amount of lignocellulosic biomass is generated as waste byproduct through agricultural practices and processing. Thus, the objective of this research is to improve the yield of enzymatic hydrolysis of wood residues by removal of lignin using alkaline wash assisted by microwave heating.

\section{Experimental}

Wood chips residue from a furniture factory (in Bucharest) were used for the experiments. The wood residue was milled and sieved. The $0.315-0.5 \mathrm{~mm}$ fraction was retained for the experiments. The wood residues were subjected to successive extractions with toluene:ethanol 1:2 solvent and then with water, for 6 hours, in a Soxhlet extractor, in order to remove wax and other extractives which can act as inhibitors for delignification and enzymatic hydrolysis. The wood residue was then dried for $48 \mathrm{~h}$ at $40^{\circ} \mathrm{C}$.

\subsection{Determination of the composition of wood residue}

The lignin and structural carbohydrates content of the wood residue (extracted) was determined according to NREL 42618 standard [4] by acid hydrolysis in two steps. In the first step, the wood residue is put into contact for 1 hour with $72 \%$ sulfuric acid. For the second step the solution is diluted to $4 \%$ sulfuric acid and autoclaved for 1 hour at $121^{\circ} \mathrm{C}$. Acid insoluble lignin is filtered, dried and weighted. The solution is neutralized and passed through $0,45 \mathrm{~mm}$ nylon filter before HPLC analysis for the determination of monosaccharides. The HPLC analysis was performed with a Jasco 2000+ System equipped with an RI detector. The monosaccharides were separated in isocratic conditions with 0,5 $\mathrm{ml} / \mathrm{min}$ ultrapure water as eluent, at $80^{\circ} \mathrm{C}$, on a Carbosep Corgel $87 \mathrm{P}(7.8 \times 300 \mathrm{~mm})$ 
Column. The results obtained for the characterization of the wood residue are presented in table 1 .

Table 1. Composition of wood residue from furniture manufacturing

\begin{tabular}{|l|l|c|}
\hline Chemical composition & Determination method & $\%$ \\
\hline Cellulose & Glucose - HPLC & 51.3 \\
\hline Hemicellulose & Xylose - HPLC & 19.6 \\
\hline Lignin & Klason lignin - gravimetry after acid hydrolysis & 25.5 \\
\hline \multirow{2}{*}{ Extractives } & Toluen+Ethanol extractives - gravimetry & 2.8 \\
\cline { 2 - 3 } & Water extractives - gravimetry & 0.8 \\
\hline
\end{tabular}

\subsection{Microwave alkaline treatment}

The treatments of the extracted wood residue were carried out in alkaline conditions, for 30 minutes, in a pressurized microwave reactor (Synthwave-Milestone). This $800 \mathrm{~mL}$ reactor is able to provide severe conditions: high temperatures (up to $300^{\circ} \mathrm{C}$ ) and pressures (up to 200 bar). The treatments were performed with a volume of $250 \mathrm{~mL}$ solution of $0.4 \mathrm{M} \mathrm{NaOH}$, $1 \mathrm{~mL}$ of Fatty acid methyl esthers (FAME), variable amount of extracted wood residue, different temperatures and 7 bar Argon pressure.

Figure 1 presents a one of the diagrams in which the experimental conditions (temperature, pressure and microwave power) are monitored and registered during alkaline treatment in the Synthwave microwave reactor. In order to maintain a constant temperature of $60^{\circ} \mathrm{C}$ inside the microwave reactor, the microwave power delivered inside the reactor was kept at 500$800 \mathrm{~W}$ in the heating region of the profile and at $150-200 \mathrm{~W}$ in the constant region of the temperature profile.

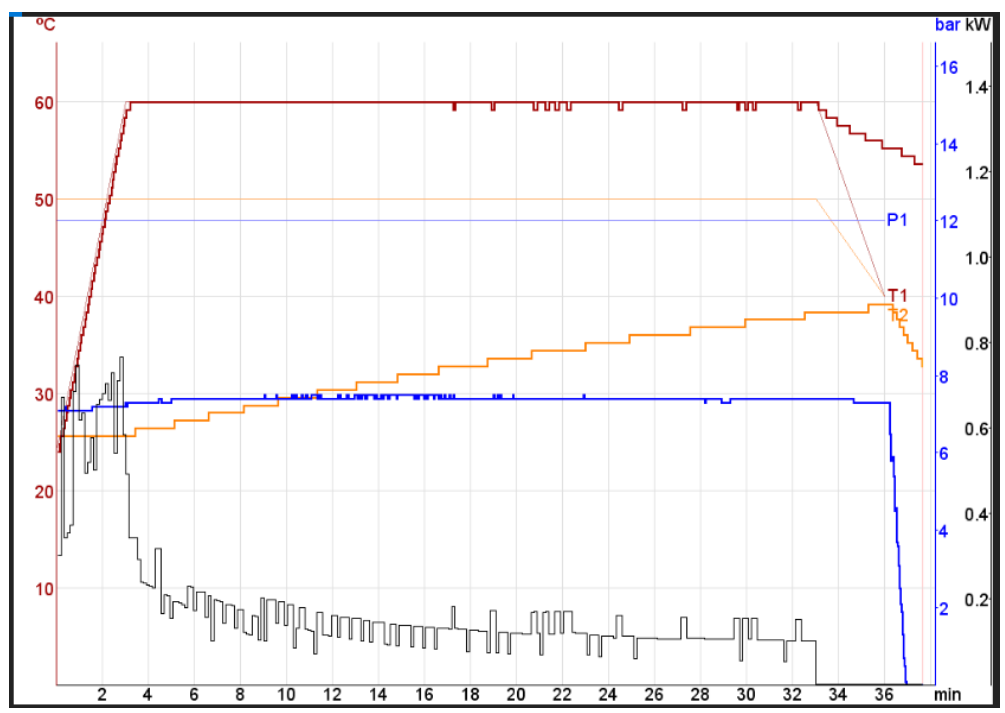

Fig. 1. Monitoring of alkaline treatment of wood residues in Synthwave microwave reactor: (Graph colour: temperature in red; pressure in blue; microwave power in black) 


\subsection{Lignin content}

The efficiency of the alkaline wash was assessed by monitoring the concentration of lignin (determined by UV absorbance at $320 \mathrm{~nm}$ against a calibration curve) from the alkaline washing solution.

\subsection{Determination of sugars from enzymatic hydrolysis}

The solid biomass obtained after the alkaline treatment was washed with distilled water until neutral $\mathrm{pH}$ and subjected to enzymatic hydrolysis. Enzymatic hydrolysis was performed at $50^{\circ} \mathrm{C}$, in a shaking water bath, with $1 \mathrm{~g}$ of treated wood residue, $25 \mathrm{~mL}$ of buffer solution $\mathrm{pH}=5$ (citric acid/ $\mathrm{Na}_{2} \mathrm{HPO}_{4}$ ) and $0.6 \mathrm{~mL}$ Celluclast $1.5 \mathrm{~L}$ enzyme. Sugar concentrations were determined every $24 \mathrm{~h}$ for three days to monitor the yield of enzymatic hydrolysis. Sugar concentration (as glucose equivalents obtained per one gram of dry mass) was determined following a modified dinitrosalicylic acid assay [5].

\subsection{Central composite design - lignin and glucose equivalents by enzymatic hydrolysis}

The treatment conditions were established according to the results obtained from a screening and characterization study carried out before constructing the experimental matrix for optimization (in Design Expert 11).

Table 2. The experimental matrix and the values determined for lignin and glucose equivalents from enzymatic hydrolysis of wood residue

\begin{tabular}{|c|c|c|c|c|c|c|c|}
\hline & & Factor 1 & Factor 2 & $\begin{array}{c}\text { Response } \\
1\end{array}$ & Response 2 & Response 3 & Response 4 \\
\hline \multirow[t]{2}{*}{ Std } & Run & A:temperature & $\| \begin{array}{c}\text { B: wood } \\
\text { residue }\end{array}$ & Lignin & $\begin{array}{c}\text { Glucose } \\
\text { Equivalents- } \\
\text { day } 1(\mathrm{EG} 1)\end{array}$ & $\begin{array}{c}\text { Glucose } \\
\text { Equivalents- } \\
\text { day } 2 \text { (EG2) }\end{array}$ & $\begin{array}{c}\text { Glucose } \\
\text { Equivalents- } \\
\text { day } 3(\mathrm{EG} 3)\end{array}$ \\
\hline & & ${ }^{0} \mathrm{C}$ & $\mathrm{g}$ & $\begin{array}{c}\mathrm{mg} / \mathrm{g} \\
\text { wood } \\
\text { residue }\end{array}$ & $\begin{array}{l}\mathrm{mg} / \mathrm{g} \text { wood } \\
\text { residue }\end{array}$ & $\begin{array}{l}\mathrm{mg} / \mathrm{g} \text { wood } \\
\text { residue }\end{array}$ & $\begin{array}{l}\mathrm{mg} / \mathrm{g} \text { wood } \\
\text { residue }\end{array}$ \\
\hline 10 & 1 & 60 & 3.75 & 19.3595 & 78.27 & 95.69 & 99.38 \\
\hline 12 & 2 & 60 & 3.75 & 19.8549 & 78.11 & 97.84 & 102.25 \\
\hline 8 & 3 & 60 & 5.52 & 15.5074 & 83.2 & 105.42 & 106.1 \\
\hline 2 & 4 & 80 & 2.5 & 26.6245 & 82.74 & 99.31 & 104.48 \\
\hline 11 & 5 & 60 & 3.75 & 18 & 80.78 & 94.25 & 100.38 \\
\hline 5 & 6 & 32 & 3.75 & 9.9068 & 77.24 & 87.7 & 92.98 \\
\hline 3 & 7 & 40 & 5 & 11.5167 & 73.04 & 87.79 & 93.45 \\
\hline 6 & 8 & 88 & 3.75 & 31.9907 & 98.61 & 109.98 & 114.77 \\
\hline 1 & 9 & 40 & 2.5 & 12.1358 & 86.04 & 101.2 & 105.05 \\
\hline 7 & 10 & 60 & 1.98 & 22.3591 & 88.75 & 92.27 & 100.28 \\
\hline 4 & 11 & 80 & 5 & 24.6122 & 93.63 & 104.39 & 115.51 \\
\hline 9 & 12 & 60 & 3.75 & 17.9974 & 85.91 & 96.46 & 104.87 \\
\hline
\end{tabular}


The screening allowed the careful selection of the most important factors that affect the lignin removal from wood residue: liquid to solid ratio (quantity of wood residue) and temperature. All experiments were carried out in duplicate. A Central Composite Design (CCD) model type was selected to be fitted with the experimental data for optimization. All experiments were carried out in duplicate. Table 2 contains the CCD experimental matrix with 12 experiments carried out with different settings of the independent factors (wood residue quantity and temperature) and the values determined experimentally for the two responses (lignin concentration and glucose equivalents).

\section{Results and discussion}

Fitting analysis of different model types to experimental values of lignin concentration indicate that the best model is linear (table 3$)$. The correlation coefficients $\left(\mathrm{R}^{2}\right.$ adjusted $=0.95$ and $\mathrm{R}^{2}$ predicted $\left.=0.91\right)$ are very close to 1 and there is a very small difference between their values.

Table 3. Fit summary for the concentration of lignin

\begin{tabular}{||r|r|r||r|r|r||}
\hline Source & Sequential p-value & Lack of Fit p-value & Adjusted R & Predicted R & \\
\hline \hline Linear & $<0.0001$ & 0.1993 & 0.9510 & 0.9170 & Suggested \\
\hline \hline $2 \mathrm{FI}$ & 0.6581 & 0.1674 & 0.9463 & 0.8842 & \\
\hline \hline Quadratic & 0.4026 & 0.1421 & 0.9471 & 0.8255 & \\
\hline \hline Cubic & 0.1752 & 0.1674 & 0.9668 & 0.5855 & Aliased \\
\hline
\end{tabular}

ANOVA of the linear model fitted for the concentration of lignin (table 4) confirm that the selected model is significant and the model is fitted. The factors that have significant effect on the concentration of lignin are the two independent factors considered: temperature and wood residue quantity.

Table 4. ANOVA of the linear model fitted for the concentration of lignin

\begin{tabular}{|c|c|c|c|c|c|c|}
\hline Source & $\begin{array}{l}\text { Sum of } \\
\text { Squares }\end{array}$ & $\mathrm{df}$ & $\begin{array}{c}\text { Mean } \\
\text { Square }\end{array}$ & F-value & $\mathrm{p}$-value & \\
\hline Model & 451.39 & 2 & 225.69 & 107.68 & $<0.0001$ & significant \\
\hline A-temperature & 432.41 & 1 & 432.41 & 206.31 & $<0.0001$ & \\
\hline B-wood residue & 18.98 & 1 & 18.98 & 9.05 & 0.0147 & \\
\hline Residual & 18.86 & 9 & 2.10 & & & \\
\hline Lack of Fit & 16.15 & 6 & 2.69 & 2.98 & 0.1993 & not significant \\
\hline Pure Error & 2.71 & 3 & 0.9034 & & & \\
\hline Cor Total & 470.25 & 11 & & & & \\
\hline
\end{tabular}

The second response - glucose equivalents from enzymatic hydrolysis of microwave alkaline treated wood residue - was monitored for 3 consecutive days (EG1, EG2 and EG3 
in table 2). The data were fitted for each individual response. In table 5 is presented the fitting for the data collected in the $3^{\text {rd }}$ day of enzymatic hydrolysis. It can be observed that a two factor interaction model is suggested.

Table 5. Fit summary for the glucose equivalents determined after 3 days of enzymatic hydrolysis of microwave alkaline treated wood residue

\begin{tabular}{|r|r|r|r|r|r||}
\hline Source & Sequential p-value & Lack of Fit p-value & Adjusted R & Predicted R & \\
\hline \hline Linear & 0.0083 & 0.1142 & 0.5787 & 0.2789 & \\
\hline \hline $2 \mathrm{FI}$ & 0.0027 & 0.4381 & 0.8563 & 0.7050 & Suggested \\
\hline Quadratic & 0.3818 & 0.4143 & 0.8610 & 0.6358 & \\
\hline \hline Cubic & 0.2414 & 0.5684 & 0.8976 & 0.6564 & Aliased \\
\hline
\end{tabular}

ANOVA of the model fitted for the glucose equivalents (table 6) confirm that the selected model is significant and the model is fitted. The factors that have significant effect on the concentration of lignin are the temperature and the interaction of temperature with wood residue quantity. The quantity of wood residue as single term does not have an significant effect on response as shown by its p-value which is well above significance level of 0.05 .

Table 6. ANOVA of the model fitted for the glucose equivalents from enzymatic hydrolysis of microwave alkaline treated wood residue (3 days)

\begin{tabular}{|l||r|r|r|r|r|l||}
\hline \multicolumn{1}{|c|}{ Source } & Sum of Squares & df & Mean Square & F-value & p-value & \\
\hline \hline Model & 477.35 & 3 & 159.12 & 22.86 & 0.0003 & significant \\
\hline \hline A-temperature & 341.99 & 1 & 341.99 & 49.12 & 0.0001 & \\
\hline B-wood residue & 7.34 & 1 & 7.34 & 1.05 & 0.3347 & \\
\hline AB & 128.03 & 1 & 128.03 & 18.39 & 0.0027 & \\
\hline \hline Residual & 55.69 & 8 & 6.96 & & \\
\hline Lack of Fit & 38.22 & 5 & 7.64 & 1.31 & 0.4381 & not significant \\
\hline \hline Pure Error & 17.47 & 3 & 5.82 & & & \\
\hline \hline Cor Total & 533.04 & 11 & & & & \\
\hline
\end{tabular}

The exploration of the experimental surfaces (figure 2) of the fitted models indicate the dominant effect of temperature as independent factor. Although this suggests that an increase of temperature would provide higher values of lignin concentration removed from the wood residue, previous experiments that were carried out showed a negative effect of very high temperatures on the performance of enzymatic hydrolysis. This can be explained by the fact that with the increase of temperature, degradation of lignin and structural carbohydrates is enhanced generating compound with inhibitory effect to the enzymes from hydrolysis [6]. 


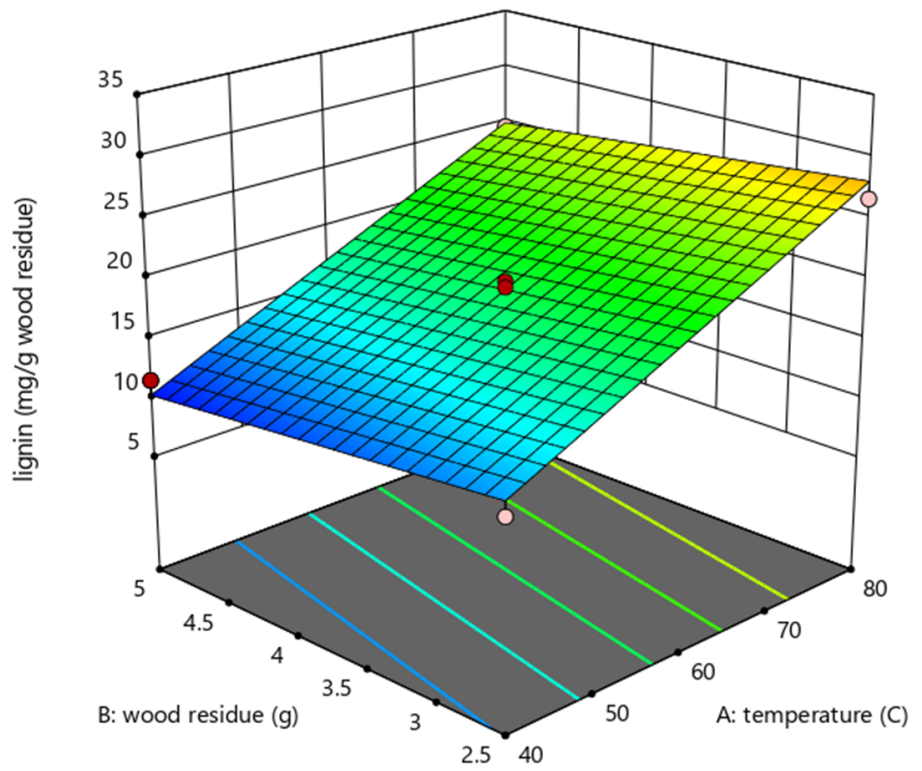

(a)

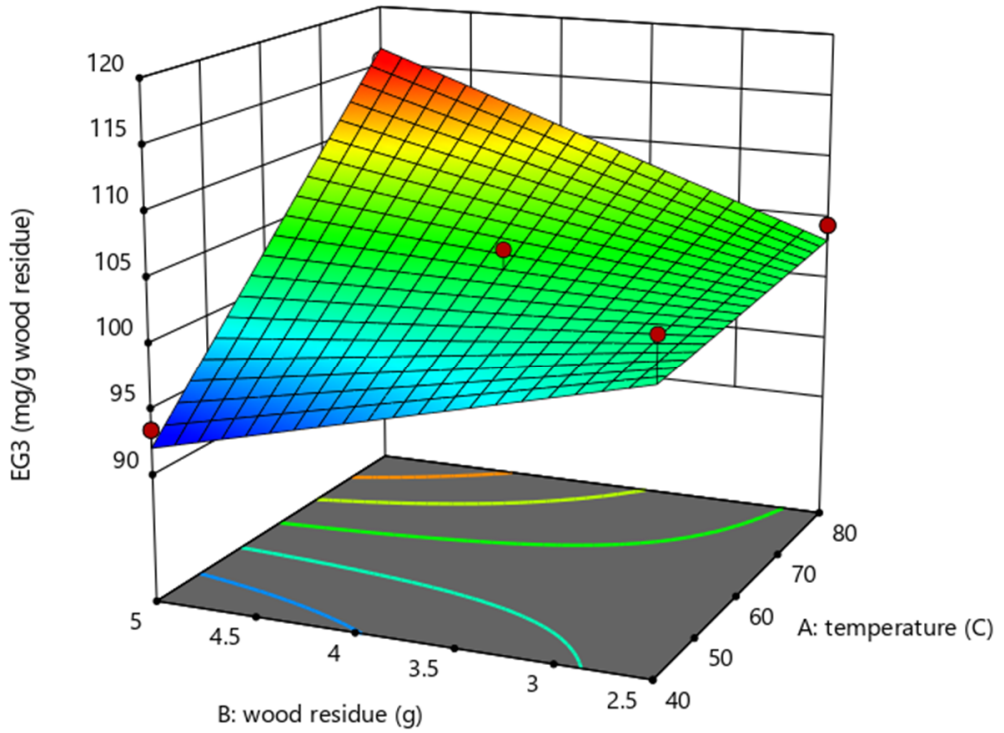

(b)

Fig. 2. 3D plot of response surfaces function of the independent factors with significant effect for: a) lignin concentration; b) glucose equivalents from enzymatic hydrolysis of microwave alkaline treated wood residue (3 days)

Optimization of experimental conditions within the experimental space was carried according to the following criteria: minimization of temperature and maximization of the solid residue quantity, lignin concentration and glucose equivalents. There are 8 solutions that satisfy the conditions imposed for the desirability function built for optimization and all 
of them are found in the same region of the response surface. One of the optimal solution (22.09 mg lignin / g wood residue and 111.67 glucose equivalents / g wood residue) indicated by the model for these optimization criteria is obtained for the following coordinates: $72^{\circ} \mathrm{C}$ and $5 \mathrm{~g}$ of wood residue (figure 3 ).
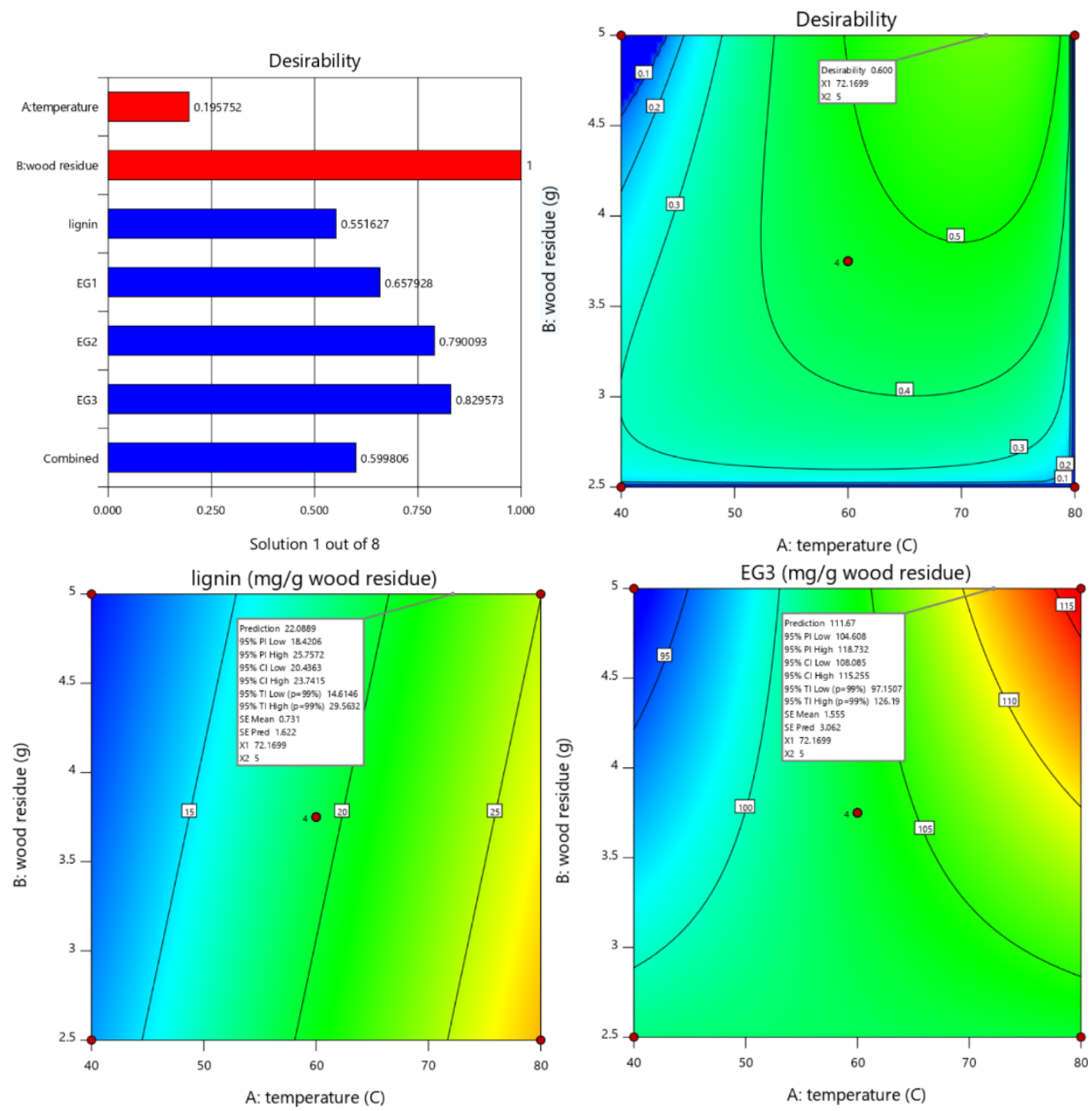

Fig. 3. Optimization (maximization) of the responses (lignin and glucose equivalents) function of the independent variables (temperature and quantity of wood residue)

\section{Conclusions}

This study is focused on improving the enzymatic hydrolysis of wood residue from furniture manufacturing by microwave alkaline treatment. Response surface methodology was used in order to find the best settings of the independent parameters (temperature and wood residue quantity) considered for the alkaline treatment. The optimization function (desirability) indicated a narrow range of settings for the temperature and the quantity of wood residue at which optimal performance is achieved: $72^{\circ} \mathrm{C}$ and $5 \mathrm{~g}$ of wood residue. 


\section{Acknowledgment}

The authors acknowledge the financial support received from the Competitiveness Operational Programme 2014 - 2020, Action 1.1.4: Attracting high-level personnel from abroad in order to enhance the RD capacity, ID project: P_37_471, MY SMIS 105145, Ultrasonic/Microwave nonconventional techniques as new tools for nonchemical and chemical processes, financed by contract: 47/05.09.2016.

\section{References}

1. Fan, J., Santomauro, F., Budarin, V. L., Whiffin, F., Abeln, F., Chantasuban, T., Gore-Lloyd, D., Henk, D., Scott, R. J., Clark, J., Chuck, C. J., J. Clean. Prod., 2018, 198, 776-784.

2. Baksi, S., Ball, A. K., Sarkar U., Banerjee, D., Wentze, A., Heinz, A., Preisig, H. A., Kuniyal, J. C., Birgen, C., Saha, S., Wittgens, B., Markussen, S., Int. J. Biol. Macromolec., 2019, 129, 634-644.

3. Pinkert, A., Goeke, D. F., Marsh, K N., Pang, S., Green Chem., 2011, 13, 31243136.

4. Sluiter, A., Determination of structural carbohydrates and lignin in biomass, NREL, 2015, 42618: 16.

5. Wood, I. P., Elston, A., Ryden, P., Bancroft, I., Roberts, I. N., Waldron, K. W., Biomass Bioenergy, 2012, 44, 117-121.

6. Jonsson, L. J., Matin, C., Biores. Technol., 2016, 199, 103-112. 